\title{
Outbreak Medical Mapping and the U.S. Nickel Epidemic: It Is Time to Implement Control and Prevention Measures
}

Nikoleta Brankov, ${ }^{1}$ Daniel Bergman, ${ }^{1}$ Alina Coldenberg, ${ }^{2}$ Sharon Jacob. ${ }^{3}$

About the Author: Nikoleta Brankov is a MD candidate (Class of 2016) at Loma Linda University School of Medicine, USA.

\section{The Experience}

Medical mapping tools visually depict demographic information identifying trends in diseases. According to the World Health Organization, a disease outbreak is defined as, "The occurrence of cases of disease in excess of what would normally be expected in a defined community." (Available from: http://www.who. int/topics/disease_outbreaks/en/, updated 2016; cited 2016 Jan 22). Geo-mapping outbreak cases serves as a vital, quick and high-yielding tool to assess the extent of an epidemic, identify vulnerable areas and evaluate a possible source.

This paper is adapted from an interactive poster presentation used to engage participants through visual representation of multiple disease outbreaks. Viewers critically analyzed maps to determine the underlying represented disease and actively

Table 1. Thirteen Steps of Outbreak Investigation with Four Current United States "Outbreaks"

\begin{tabular}{lcccc}
\hline \multicolumn{1}{c}{ Thirteen Steps } & $\begin{array}{c}\text { Map A } \\
\text { (Ebola } \\
\text { virus) }\end{array}$ & $\begin{array}{c}\text { Map B } \\
\text { (Measles) }\end{array}$ & $\begin{array}{c}\text { Map C } \\
\text { (Enterovi- } \\
\text { rus D-68) }\end{array}$ & $\begin{array}{c}\text { Map D } \\
\text { (pediatric } \\
\text { Ni-ACD) }\end{array}$ \\
\hline Prepare for field work & $\mathrm{X}$ & $\mathrm{X}$ & $\mathrm{X}$ & $\mathrm{X}$ \\
\hline Establish existence of outbreak & $\mathrm{X}$ & $\mathrm{X}$ & $\mathrm{X}$ & $\mathrm{X}$ \\
\hline Verify the diagnosis & $\mathrm{X}$ & $\mathrm{X}$ & $\mathrm{X}$ & $\mathrm{X}$ \\
\hline Construct a working case definition & $\mathrm{X}$ & $\mathrm{X}$ & $\mathrm{X}$ & $\mathrm{X}$ \\
\hline Find cases systematically and record information & $\mathrm{X}$ & $\mathrm{X}$ & $\mathrm{X}$ & $\mathrm{X}$ \\
\hline Perform descriptive epidemiology & $\mathrm{X}$ & $\mathrm{X}$ & $\mathrm{X}$ & $\mathrm{X}$ \\
\hline Develop hypotheses & $\mathrm{X}$ & $\mathrm{X}$ & $\mathrm{X}$ & $\mathrm{X}$ \\
\hline Evaluate hypotheses epidemiologically & $\mathrm{X}$ & $\mathrm{X}$ & $\mathrm{X}$ & $\mathrm{X}$ \\
\hline Reconsider, redefine, C re-evaluate hypotheses & $\mathrm{X}$ & $\mathrm{X}$ & $\mathrm{X}$ & $\mathrm{X}$ \\
\hline Compare and reconcile with environmental studies & $\mathrm{X}$ & $\mathrm{X}$ & $\mathrm{X}$ & $\mathrm{X}$ \\
\hline Implement control and prevention measures & $\mathrm{X}$ & $\mathrm{X}$ & $\mathrm{X}$ & $\mathrm{O}$ \\
\hline Initiate or maintain surveillance & $\mathrm{X}$ & $\mathrm{X}$ & $\mathrm{X}$ & $\mathrm{X}$ \\
\hline Communicate findings & $\mathrm{X}$ & $\mathrm{X}$ & $\mathrm{X}$ & $\mathrm{X}$ \\
\hline
\end{tabular}

The Thirteen Steps of an Outbreak Investigation, with Map D depicting 12 out of 13 criteria met for nicke allergic contact dermatitis-strongly supporting its identification as an outbreak. participated in the interactive experience processing through the thirteen steps of an outbreak investigation (Table 1). (Available from: http://www.cdc.gov/ophss/csels/dsepd/ss1978/lesson6/section2.html, updated 2012 May 18; cited 2016 Feb 6).

The outbreak data of four United States medical conditions Currently in the news were geographically presented (Maps A-D). Data was gathered via the Centers for Disease Control and Prevention (CDC) records and via the Loma Linda Pediatric Contact Dermatitis Registry.' Data from the pediatric nickel dermatitis registry was compared to the 13 principle steps for outbreak control to allow participants to investigate and identify whether nickel contact dermatitis in U.S. children met the 13 criteria for an outbreak. Twenty participants completed the map challenge by reviewing and interacting with the four comparative maps on the poster.

Map A depicted the Ebola virus outbreak in 2014, where there were four U.S. confirmed cases ( 3 healthcare workers). The Ebola epidemic in 2014 was the largest in world history, affecting multiple countries in West Africa. Map B depicted the Measles virus outbreak, where from December 28, 2014 to February 8, 2015, 125 people from seven states [CA (110), AZ (7), UT (3), WA (2), CO (1), OR (1), NE (1)] were reported to have this disease. This outbreak started from a traveler who became infected overseas with measles, and then visited Southern California while infectious. Map C depicted the Enterovirus D68 (EV-D68) virus outbreak that occurred from mid-August 2014 to January 15,2015 . The CDC confirmed a total of 1,153 cases during this time period. EV-D68 can cause fever, rhinorrhea, sneezing, cough, body and muscle aches and possibly severe symptoms of wheezing and difficulty breathing.

Map D shown in the interactive poster session (Figure 1) defines in red where at least one pediatric nickel allergic contact dermatitis (Ni-ACD) case has been reported in peer-reviewed literature, in pink where there was at least one confirmed case of nickel dermatitis, but not reported in peer-reviewed literature, and in white the states for which there is insufficient data. The disease depicted in Map D meets 12/13 criteria strongly supporting its identification as an "outbreak" (Table 1).

Loma Linda University School of Medicine, California, USA

${ }^{2}$ Preliminary Internal Medicine and Dermatology, University of California, San Diego Medical Center, California, USA.

${ }^{3}$ Department of Dermatology, Loma Linda University School of Medicine, California, USA.

\section{Correspondence:}

Sharon Jacob.

Address: Department of Dermatology, Loma Linda University School of Medicine, 11139 Anderson St, Loma Linda, CA 92350, USA.

Email: sjacob@contactderm.net 


\section{Experience}

Participants were given basic information on the three, Centers for Disease Control and Prevention, maps depicting outbreak diseases. In addition, extensive educational information was provided on allergic contact dermatitis, the fourth condition depicted in Map D, to demonstrate that this condition was an unrecognized outbreak. Specifically, participants were educated with regards to the classic presentations of the disease, how to recognize it and how to prevent it. Notably, nickel is the most commonly detected contact allergen in both adults and children worldwide. ${ }^{2}$ It is found in a wide range of items from jewelry, zippers, buttons, belt buckles to coins, cell phones, and electronics. Nickel can even be found in certain foods (chocolate, oats, and pinto beans). ${ }^{3}$

Pediatric Ni-ACD is a common and debilitating under-reported disease with a reported prevalence of nickel sensitization between $13.3 \%-24.5 \% .4-5$ In the 1980 's, Denmark and the European Union (EU) instated legislation to limit nickel content in products in contact with the skin. This resulted in significantly decreased rates of sensitization among Danish children o to 18 years of age from $24.8 \%$ to $9.2 \%$ between 1985 and 1998 , with similar reductions in sensitization in the EU. ${ }^{6-7}$ Current estimates gauge that the US has similar sensitization rates to those in Europe, pre-regulation, translating to a cost of 5.7 billion US dollars/year. ${ }^{8-9}$

In conclusion, chronic undeclared epidemics can meet the criteria for an outbreak in need of control. U.S. Pediatric Ni-ACD is largely preventable and efforts should be made to reduce this U.S. public health burden by reducing exposure to items with high nickel release. Public education and legislation are vital in bringing in change. In August 2015, the American Academy of Dermatology adopted a nickel safety position statement calling for public awareness of nickel sensitivity as an ongoing health epidemic. (Available from: https://www.aad.org/Forms/Policies/ ps.aspx, updated 2015 August 22; cited 2016 May 24). This interactive poster session revealed that the majority of participants could recognize measles with the incident cases being in proximity geographically and the outbreak having recently been in the news. However, far fewer people were aware of the nickel epidemic. The time has come for the U.S. to adopt a European Union-like nickel safety directive and implement control and prevention measures.
Figure 1. Pediatric Nickel Allergic Dermatitis - Map D of Interactive Poster Session

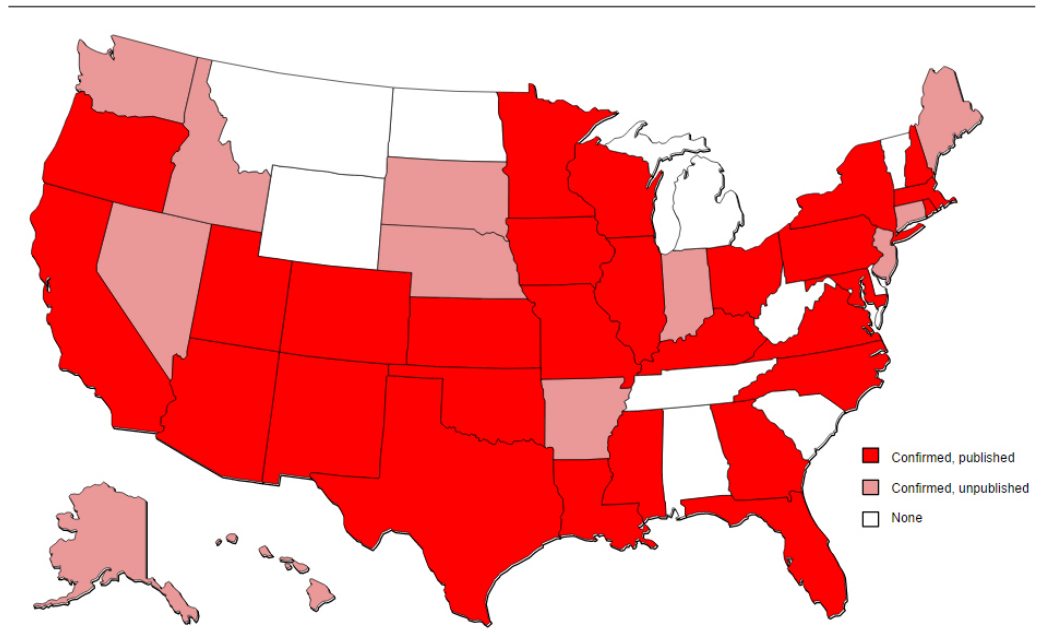

States with at least one nickel allergic contact dermatitis case reported in peer-reviewed literature are identified in Red (location based on affiliation of corresponding author, unless otherwise noted or confirmed). States with at least one confirmed case of nickel dermatitis, but no reported cases in peer-reviewed literature are identified in Pink. States for which there is insufficient data are identified in White.

\section{References}

1. Jacob SE, Goldenberg A, Silverberg N, Fonacier L, Brod B, Usatine R, et al. Coblin's copper - the time for a nickel-directed US health policy is here. The Dermatologist. 2015 Mar;23(3).

2. Belloni Fortina A, Romano I, Peserico A, Eichenfield LF. Contact sensitization in very young children. J Am Acad Dermatol. 2011 0ct;65(4):772-9.

3. Sharma AD. Low nickel diet in dermatology. Indian J Dermatol. 2013 May; 58(3):240.

4. Coldenberg A, Vassantachart J, Lin EJ, Lampel HP, Jacob SE. Nickel allergy in adults in the U.S.: 1962 to 2015. Dermatitis. 2015 Sep-0ct;26(5):216-23.

5. Barros MA, Baptista A, Correia TM, Azevedo F. Patch testing in children: a study of 562 schoolchildren. Contact Dermatitis. 1991 Sep;25(3):156-9.

6. Johansen Jd, Menné T, Christophersen J, Kaaber K, Veien N. Changes in the pattern of sensitization to common contact allergens in Denmark between 1985-86 and 1997-98, with a special view to the effect of preventive strategies. Br J Dermatol. 2000 Mar;142(3):490-5.

7. Thyssen JP, Uter W, McFadden J, Menné T, Spiewak R, Vigan M, et al. The EU Nickel Directive revisited-future steps towards better protection against nickel allergy. Contact Dermatitis. 2011 Mar;64(3):121-5.

8. Goldenberg A, Jacob SE. Demographics of US pediatric contact dermatitis registry providers. Dermatitis. 2015 Jul-Aug;26(4):184-8.

9. Jacob SE, Goldenberg A, Pelletier JL, Fonacier LS, Usatine R, Silverberg $\mathrm{N}$. Nickel allergy and our children's health: a review of indexed cases and a view of future prevention. Pediatr Dermatol. 2015 Nov-Dec;32(6):779-85.

\section{Acknowledgments}

None.

Conflict of Interest Statement a Funding

The author has no funding, financial relationships or conflicts of interest to disclose.

\section{Author Contributions}

Conceptualization, Data collection, Data analysis and interpretation, Writing, Critical revision of the manuscript, Approval of the final version: $N B, D B, A G, S J$.

Cite as:

Brankov N, Bergman D, Goldenberg A, Jacob S. Outbreak medical mapping and the U.S. nickel epidemic: it is time to implement control and prevention measures. Int J Med Students. 2016 Jan-Apr;4(1):36-7. 